[Agr. Biol. Chem., Vol. 35, No. 3, p. $441 \sim 443,1971]$

\title{
Structures of Gibberellins $A_{33}$ and $A_{34}$ from Immature Seeds of Calonyction aculeatum
}

Sir:

The isolation of gibberellins from immature seeds of evening-glory (Calonyction aculeatum) and the structural determination of two new gibberellins, $\mathrm{GA}_{30}$ and $\mathrm{GA}_{31}$, have been previously reported. ${ }^{1 \prime}$ Here we report the structural determination of other two new gibberellins, $\mathrm{GA}_{33}$ and $\mathrm{GA}_{34}$.

From $23 \mathrm{~kg}$ of immature seeds of eveningglory $\mathrm{GA}_{33}\left(\mathrm{mp} 219 \sim 221^{\circ} \mathrm{C}\right.$ ) and $\mathrm{GA}_{34}(\mathrm{mp}$ $218 \sim 219^{\circ} \mathrm{C}$ ) were obtained in yields of $17 \mathrm{mg}$ and $12 \mathrm{mg}$, respectively, through the procedures already described. ${ }^{1 "}$ On treatment with diazomethane $\mathrm{GA}_{33}$ affords a methyl ester, the high resolution mass spectrum of which shows its molecular formula to be $\mathrm{C}_{20} \mathrm{H}_{24} \mathrm{O}_{7}$. The ester also reveals M-18, M-32, M-44, M-46, M-50, M-60, M-78 and M-122 peaks, which constitute a pattern characteristic of $\mathrm{C}_{19}$ gibberellin methyl esters." Since the presence of a $3 \mathrm{H}$ singlet due to a methoxycarbonyl in the NMR spectrum of the methyl ester shows $\mathrm{GA}_{33}$ to be a monocarboxylic acid, the molecular formula $\mathrm{C}_{19} \mathrm{H}_{22} \mathrm{O}_{7}$ is assigned to $\mathrm{GA}_{33}$. The functional groups in $\mathrm{GA}_{33}$ are summarized in Table I. The presence of an $\alpha$-oriented hydroxyl group at $\mathrm{C}-12$ in ent-gibberellane skeleton (I) is shown by a $1 \mathrm{H}$ triplet at $\tau 6.26$ in NMR spectrum measured in deuteroacetone as in the cases of $\mathrm{GA}_{30}$ and $\mathrm{GA}_{31}$. An oxidation product of $\mathrm{GA}_{33}$ obtained by the Jones reagent shows a UV absorption maximum at $283 \mathrm{~m} \mu$

1) N. Murofushi, T. Yokota and N. Takahashi, Agr. Biol. Chem., 34, 1436 (1970).

2) N. Takahashi, N. Murofushi, S. Tamura, N. Wasada, H. Hoshino, T. Tsuchiya, S. Sasaki, T. Aoyama and E. Watanabe, Org. Mass Spectrometry, 2, 711 (1969).
Table I. Functional Groups of $\mathrm{GA}_{93}$

\begin{tabular}{lrl}
\hline \multicolumn{2}{c}{ IR (cm ${ }^{-1}$, nujol) } & NMR $(\tau$, in deuteroacetone $)$ \\
\hline $2 \mathrm{H}-\mathrm{C}-\mathrm{CH}$ & 3470 & $5.58(1 \mathrm{H}, \mathrm{d}), 6.26(1 \mathrm{H}, \mathrm{t})$ \\
$1 \mathrm{COOH}$ & 1696 & \\
$1, \mathrm{C}=\mathrm{O}$ & 1733 & \\
$1 \gamma$-lactone & 1794 & \\
$1 \mathrm{C}=\mathrm{CH}_{2}$ & 1658 & $5.02(1 \mathrm{H}, \mathrm{s}), 4.92(1 \mathrm{H}, \mathrm{s})$ \\
$1-\mathrm{C}-\mathrm{CH}_{3}$ & & $8.89(3 \mathrm{H}, \mathrm{s})$ \\
$1 \mathrm{CO}-\mathrm{CH}_{2}-$ & & $7.46(1 \mathrm{H}, \mathrm{d}), 7.06(1 \mathrm{H}, \mathrm{q})$ \\
\hline $\mathrm{CH}(\mathrm{OH})-$ & & \\
\hline
\end{tabular}

( $\varepsilon 360)$, which is characteristic of $\beta, \gamma$-unsaturated ketones as in $\mathrm{GA}_{26}$, the presence of the $\mathrm{C}-12$ hydroxyl group being confirmed. In the NMR spectrum of $\mathrm{GA}_{33}$ there exist a $1 \mathrm{H}$ doublet at $z$ 7.46 and a $1 \mathrm{H}$ quartet at $\tau 7.06$, which are geminally coupled with one another $(J=17 \mathrm{cps})$, indicating the presence of a methylene group adjacent to a carbonyl. The proton, to which the latter signal is assigned, is further coupled with a carbinyl proton $(\tau 5.58, J=5 \mathrm{cps})$. These evidences indicate the presence of the partial structure $-\mathrm{CO}-\mathrm{CH}_{2}-\mathrm{CH}(\mathrm{OH})_{-}$, which must be contained in the ring $\mathrm{A}$. Further, the low $\tau$ value of the $\mathrm{G}-5$ proton ( $\tau$ 6.52), which is coupled with the $\mathrm{C}-6$ proton $(J=11 \mathrm{cps})$ to constitute a pattern characteristic of gibberellins, indicates that a hydroxyl exists at $\mathrm{C}-1$ or $\mathrm{C}-3$ in $\beta$ configuration, suggesting possible two structures II and III for $\mathrm{GA}_{39}$. Structure II was chosen of the two alternatives on the following basis. A hydrogenolysis product (IV) of $\mathrm{GA}_{3}$ methyl ester was methylated with diazomethane and then oxidized with the Jones 


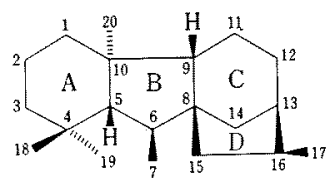

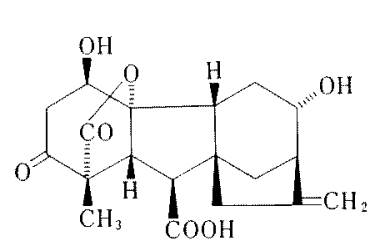

II

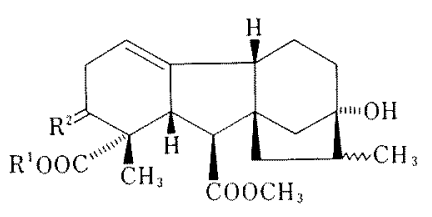

$\mathrm{N} \mathrm{R}^{1}=\mathrm{H}, \quad \mathrm{R}^{2}=\beta \mathrm{OH}, \quad \alpha \mathrm{H}$

$\mathrm{V} \mathrm{R}=\mathrm{RH}_{3}, \quad \mathrm{R}^{2}=\mathrm{O}$

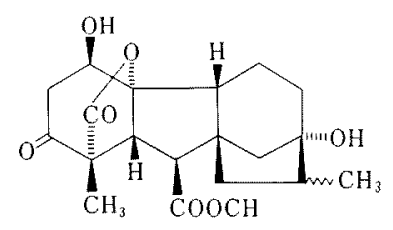

VII

reagent to afford a keto-ester (V). The ester was oxidized with $m$-chloroperbenzoic acid to afford an epoxide (VI). Treatment of VI with dilute sulfuric acid resulted in cleavage of the epoxide and simultaneous lactonization to give VII. The signals of C-1, C-2, C-5, C-6 and $\mathrm{C}-18$ protons in the NMR spectrum of VII is quite similar to those of $\mathrm{GA}_{33}$ methyl ester; VII and $\mathrm{GA}_{33}$ show an identical $\mathrm{CD}$ curve with positive Cotton effect at $296 \mathrm{~m} \mu(\theta=10,000)$. The other spectral data are in good agreement with the stereochemical expression of II for $\mathrm{GA}_{33}$.

In the same way as in $\mathrm{GA}_{33}$, the molecular formulas, $\mathrm{C}_{19} \mathrm{H}_{24} \mathrm{O}_{6}$ and $\mathrm{C}_{20} \mathrm{H}_{26} \mathrm{O}_{6}$, are assigned to $\mathrm{GA}_{34}$ and its methyl ester, respectively; their spectral properties show that $\mathrm{GA}_{34}$ is a $\mathrm{C}_{19}$-gibberellin. The functional groups of $\mathrm{GA}_{34}$

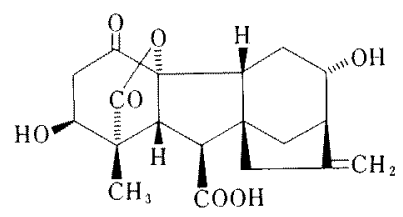

III

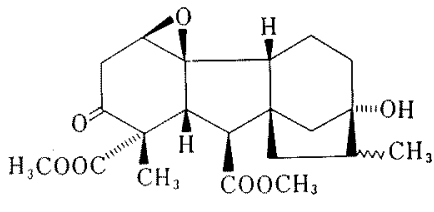

VI

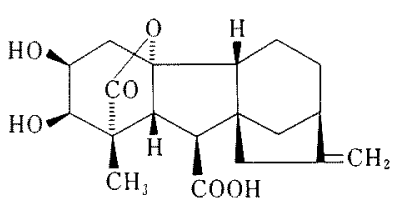

VIII

are summarized in Table II. The presence of two hydroxyl groups in $\mathrm{GA}_{34}$ is confirmed

TABLE II. FUnCtional Groups of $\mathrm{GA}_{34}$

\begin{tabular}{lll}
\hline IR $\left(\mathrm{cm}^{-1}\right.$, nujol $)$ & NMR $(\tau$, in deuteroacetone $)$ \\
\hline $2 \mathrm{H}-\mathrm{C}-\mathrm{OH}$ & 3340 & $6.25(1 \mathrm{H}, \mathrm{m}), 6.38(1 \mathrm{H}, \mathrm{d})$ \\
$1 \mathrm{COOH}$ & $\left.1728^{a}\right)$ & \\
$1 \gamma$-lactone & $1776^{a}$ & \\
$1 / \mathrm{C}=\mathrm{CH}_{2}$ & 1655 & $5.16(1 \mathrm{H}, \mathrm{s}), 5.04(1 \mathrm{H}, \mathrm{s})$ \\
$1-\mathrm{C}-\mathrm{CH}_{3}$ & & $8.85(3 \mathrm{H}, \mathrm{s})$
\end{tabular}

a) Determined in dioxane.

by the mass spectrum of the trimethylsilyl ether of its methyl ester (parent peak, $m / e$ 506). In the NMR spectrum (in deuteroace- 
tone) a $3 \mathrm{H}$ singlet due to the $\mathrm{G}-18$ methyl protons and a $1 \mathrm{H}$ doublet due to the $\mathrm{C}-5$ proton are observed at $\tau 8.85$ and $\tau 6.75$, respectively. These signals shift to $\tau 8.29$ and $\tau 6.02$, respectively when measured in deuteropyridine, indicating that one of the hydroxyl groups is located at $\mathrm{C}-3$ in $\beta$ axial. The presence of 1,2-diol is shown by rapid consumption of periodate and by easy formation of an acetonide derivative of $\mathrm{GA}_{34}$ methyl ester. The NMR pattern in the carbinyl region is quite similar to those of $\mathrm{GA}_{8}, \mathrm{GA}_{26}$ and $\mathrm{GA}_{27}$. Since the $\mathrm{C}-3$ hydroxyl group is in $\beta$ axial, the $\mathrm{C}-2$ hydroxyl group must be in $\beta$ equatorial. Thus, structure VIII was proposed to $\mathrm{GA}_{34}$.
The authors wish to express their thanks to Professors K. Kawatei and K. Tsunoda of this Faculty and to Sankyo Co. for their help in cultivation of evening-glory, to Drs. T. Tsuchiya and N. Wasada of Government Chemical Industrial Research Institute (Tokyo) for measuring high resolution mass spectra, and to Mr. K. Aizawa and his colleagues of this Department for measuring IR, NMR and mass spectra.

\author{
Noboru MurofushI \\ Takao Yokota \\ Nobutaka TAKAHASHI
}

Department of Agricultural Chemistry,

The University of Tokyo,

Bunkyo-ku, Tokyo

Received December 14, 1970 